\title{
Governing Quintuple Helix Innovation: Urban Living Labs and Socio-Ecological Entrepreneurship
}

\author{
Bastiaan Baccarne, Sara Logghe, Dimitri Schuurman, and Lieven De Marez
}

\author{
"Cities are never random. No matter how chaotic they might") \\ seem, everything about them grows out of a need to solve a \\ problem. In fact, a city is nothing more than a solution to a \\ problem, that in turn creates more problems that need more \\ solutions, until towers rise, roads widen, bridges are built, and \\ millions of people are caught up in a mad race to feed the \\ problem-solving, problem-creating frenzy.
}

\author{
Neal Shusterman \\ Author of young-adult fiction \\ In Downsiders (2001)
}

\begin{abstract}
Growing urbanization puts pressure on both social and ecological systems. This pressure raises complex and multi-facetted challenges that can only be tackled by collaborative and distributed innovation development processes. However, theoretical frameworks that assess such collaborations are often very conceptual, with little focus on the actual governance mechanisms that facilitate them. This article studies the urban living lab concept as an inter-organizational design and multi-stakeholder innovation development process to govern the quintuple helix model for innovation by means of an action research based multidimensional case study design, which focuses on the concepts of innovation democracy, mode 3 knowledge production, the innovation ecosystem as a system of societal subsystems, and socio-ecological transition. In this way, we provide a more profound understanding of such innovation processes to tackle socio-ecological challenges by means of public-private interactions driven by eco-entrepreneurship.
\end{abstract}

\section{Introduction}

Society is confronted with challenges of an increasingly complex and global nature. It is hard for a single societal actor to come up with the right solutions, given that knowledge and resources are distributed among a wide network of stakeholders (Bogers \& West, 2012). Thus, innovation actors must reach out to external knowledge. Among the most pressing and interesting challenges are those involving public value and market failure. As urbanization continues at a rapid pace, socio-ecological systems are put under heavy pressure, inducing ecological issues such as global warming, decreasing air quality, increasing hazardous emissions, and geological instability. Although a sense of urgency for solutions is widespread, society is still struggling to find an adequate, sustainable, and agile way to react. It is clear, however, that these challenges need to be dealt with by a diverse ecosystem of private actors, universities, civil society, and politics.

Nevertheless, in innovation management theory, the question is not why, but rather how such challenges can be tackled. In the collaborative knowledge production and innovation management literature, one of the frameworks that attempt to take the natural environment into account is the "quintuple helix model" for innovation (Carayannis \& Campbell, 2010). Although this rather recent analytical framework is very promising, only little empirical evidence exists that explores its possibilities and limitations. On top of that, this model is mainly applied to assess larger innovation ecosystems such as national or regional innovation systems, and to a lesser extent to the innovation development process. 


\section{Quintuple Helix Innovation: Urban Living Labs and Socio-Ecological Entrepreneurship} Bastiaan Baccarne, Sara Logghe, Dimitri Schuurman, and Lieven De Marez

Therefore, this article focuses on the specific governance mechanisms that can facilitate quintuple helix innovation at the level of the individual innovation development process. More specifically, the "urban living lab" concept is explored as an inter-organizational R\&D design and multi-stakeholder innovation development process to govern the quintuple helix model for innovation. Hence, this article contributes to a more profound understanding of local collaborative innovation processes that are designed to tackle socio-ecological challenges by means of public-private interactions, driven by eco-entrepreneurship. In other words: How can urban living labs be a way to put quintuple helix innovation into practice?

First, we discuss the urbanization process to better understand the context in which these challenges occur. Next, we relate this evolution to collaborative innovation literature, and elaborate on the (urban) living lab concept as a way to put this into practice. Finally, we develop an analytical framework, which is structured along the concepts of innovation democracy, mode 3 knowledge production, the innovation ecosystem as a system of societal subsystems, and socio-ecological transition, and apply this framework to two urban living lab cases.

\section{Background}

Urbanization, socio-ecological challenges, and urban innovation

The speed of urbanization is overwhelming (Bocquier, 2005). This rapid evolution puts pressure on social, physical, and ecological systems as city populations continue to grow and more and more people are live in densely populated areas. This pressure, in combination with the associated emergence of grand societal challenges and rapid technological evolutions, forces cities to look for new ways to reinvent themselves (Atkinson, 1998; Foth, 2009; Viitanen \& Kingston, 2014).

In practice, however, local governments often lack the capability and resources to tackle these challenges in a flexible way (O'Flynn, 2007). In the search for new ways to cope with this tension, transparency and close interaction with grassroots initiatives are increasingly put forward as solutions to overcome this gap (Buscher et al., 2010). This approach involves a wide variety of urban stakeholders (e.g., citizens, universities, enterprises, non-governmental organizations), thereby potentially leveraging the distributed knowledge in the urban environment.
Nevertheless, these interactions need to be governed and in some way be able to connect the traditional topdown approach with a grassroots or bottom-up approach. This strategy is in line with the open or distributed innovation approach (Bogers \& West, 2012; Chesbrough, 2003), causing city governments to question the dominant paradigm of top-down innovation development, and implementation, and to experiment with innovation processes together with, and even by, citizens and other organizations in the urban environment (Paskaleva, 2011).

\section{Understanding collaborative innovation processes}

A useful framework for the analysis of such complex collaborative innovation networks is the "triple helix" model for innovation (Etzkowitz \& Leydesdorff, 1995), which originally focused on collaboration and knowledge production in university-government-industry partnerships (Etzkowitz \& Leydesdorff, 2000). It was later expanded with a fourth helix to incorporate civil society (Carayannis \& Campbell, 2009).

However, from a socio-ecological systems point of view, the urban evolutions described above also need to be studied as changes in human-environment systems (Young et al., 2006).

Hence, a socio-ecological systems approach integrates social and ecological systems thinking in a holistic way to assess "system threats" (Berkes et al., 2000). Such socio-ecological systems can be considered complex units in which resources are exchanged and regulated by social and ecological systems (Berkes et al., 2002; Machlis et al., 1997), which makes them interesting conceptual frameworks to assess socio-ecological innovation in an urban environment. They also encourage the integration of this logic and analytical dimensions in the innovation ecosystem literature. Therefore, a fifth helix should be added to the quadruple helix model, to also take the natural environment into account (Carayannis \& Campbell, 2010). This is what makes the quintuple helix model for innovation an interesting and valuable model to analyze innovation ecosystems.

To explain processes of knowledge exchange that take place in such collaborative innovation ecosystems, these models apply the concepts of "mode 3" knowledge production and "open innovation diplomacy". Mode 3 knowledge production is conceptualized as an extension of mode 1 knowledge production (traditional research by universities) (Godin \& Gingras, 2000) and mode 2 knowledge production (knowledge that is gen- 


\section{Quintuple Helix Innovation: Urban Living Labs and Socio-Ecological Entrepreneurship} Bastiaan Baccarne, Sara Logghe, Dimitri Schuurman, and Lieven De Marez

erated when mode 1 knowledge is applied and put into practice) (Gibbons et al., 1994; Nowotny et al., 2003). Mode 3 adds a third component to this representation of knowledge production by highlighting the overarching system in which this knowledge is produced and exchanged (i.e., innovation networks and knowledge clusters). "Open innovation diplomacy", on the other hand, is used to describe the way in which different organizations and ecosystem are able to collaborate and bridge the divides that exist between traditionally separated domains (this can be social, organizational, cultural, or technological) (Carayannis \& Campbell, 2011).

\section{Living labs and the urban environment}

Triple, quadruple, and quintuple helix models have a strong theoretical nature. One approach that tries to facilitate such models in a structured way is the "living lab" approach, which can be defined as an ecosystem approach in which end users and other stakeholders are involved in the development of an innovation over a long period of time, in a real-life environment, following an iterative process (Niitamo \& Kulkki, 2006; Schuurman et al., 2012) applying multi-method, usercentric innovation research with a strong focus on user empowerment and real-world experimentation (Følstad, 2008; Schuurman et al., 2013; Ståhlbröst, 2008). Furthermore, it offers a structured process and environment to govern input from a wide variety of stakeholders and research methods (Eriksson et al., 2006; Ståhlbröst \& Holst, 2012).

In the urban environment, living labs gain importance as a way to govern (complex) urban collaborative innovation processes (Buscher et al., 2010; Paskaleva, 2011). Although the process is similar, urban living labs have a distinct nature because the focus is on civic participation, and the output is aimed at increasing quality of life in the city rather than the development of a commercial product or service (Baccarne et al., 2014). As such, urban living labs are an instrument to include a wide variety of stakeholders (citizens, municipalities, entrepreneurs, etc.) in the search for innovations that meet local socio-ecological challenges (Franz, 2014). Juujärvi and Pesso (2013) define an urban living labs as "a physical region in which different stakeholders form public-private-people partnerships of public agencies, firms, universities, and users collaborate to create, prototype, validate, and test new technologies, services, products, and systems in real-life contexts".

However, despite strong European support, this research and development concept is still struggling for an adequate and more profound theoretical anchoring and remains too much of a "practice-based" concept (Kviselius et al., 2008; Schuurman, 2015). Quintuple helix (-related) concepts provide potentially valuable tools and assumptions for the assessment and theoretical foundation of the more practical oriented living lab literature, embedded within a broader socio-ecological system. On the other hand, the living lab literature might provide a practical framework to put quintuple helix innovation into practice. Furthermore, exploring the quintuple helix model in the context of urban innovation contributes to a more profound understanding of urban innovation in relation with socio-ecological transition in urban areas.

\section{Methodology}

\section{Research design}

To investigate quintuple helix innovation in relation to urban living labs, we conducted an action research study (Reason \& Bradbury, 2001) in which we purposefully designed and participated as researchers in two urban living lab projects. This approach allowed us direct access and control over the projects, as well as more profound insights on the observed phenomena. The analysis is structured following the principles of a multidimensional case study design (Eisenhardt, 1989; Yin, 1984). The unit of analysis in this design is the individual project-centric innovation ecosystem.

The two cases had to: i) focus on eco-entrepreneurship, ii) target the urban environment, iii) be open for the researcher team to shape and mold (cfr. action research), iv) be collaborative in nature, and v) encompass an innovation development process. The two selected research projects were instigated by start-up organizations with socio-ecological goals in the urban environment, and they were both incubated by a regional incubating organization (funded by the Flemish government in order to stimulate innovation in ICT). Both projects involved the set-up of an ad hoc collaborative network of stakeholders and a structured, semiformal adaptive iterative product development process. Project A was set up around the development of an interactive platform to engage, collaborate, and communicate on the topic of air quality. Project B concerned the development of a peer-to-peer car sharing initiative for electric vehicles.

Both living lab processes were designed along principles whereby the living lab project had to: i) incorporate multiple iterations (Pierson \& Lievens, 2005; Schaffers \& Budweg, 2009), ii) involve multiple stakeholders (Feurstein et al., 2008; Frissen \& Lieshout, 2004; 


\section{Quintuple Helix Innovation: Urban Living Labs and Socio-Ecological Entrepreneurship} Bastiaan Baccarne, Sara Logghe, Dimitri Schuurman, and Lieven De Marez

Juujärvi \& Pesso, 2013), iii) be driven by multi-method research (De Moor et al., 2010; Eriksson et al., 2006; Niitamo \& Kulkki, 2006), iv) involve real-world experimentation (Følstad, 2008; Niitamo \& Kulkki, 2006), and v) be based on active co-creation by stakeholders (Følstad, 2008; Schumacher \& Niitamo, 2008; Schuurman et al., 2012; Ståhlbröst, 2008). In line with the conceptualization of an urban living lab, the local government was a required stakeholder in the innovation development ecosystem. Between each iteration, steering committee meetings were held to evaluate the process and modify it if necessary. These steering committees consisted of the researchers, the project managers, and the project instigators (eco-entrepreneurs) (see also Rits et al., 2015).

\section{Research framework}

A beneficial aspect of case study design is the opportunity to include multiple sources of evidence, thus enhancing the validity of the analysis through data triangulation (Yin, 1984). The sources of evidence in this study include ethnographic field notes, in-depth interviews, email communications, meeting reports of steering committees, initial project proposals, project reports, and project deliverables. These sources of evidence were coded and interpreted by the author team following an analytical protocol (Yin, 1984) that encompassed the four dimensions that are key elements in the literature on innovation ecosystems, and in particular the quintuple helix model and socio-ecological systems:

1. Innovation diplomacy: the praxis of bridging barriers between traditionally separated actors and fields (Carayannis \& Campbell, 2011).

Assumption: properly targeted initiatives are able to connect know-how, tacit knowledge, creativity, and formal knowledge between different domains and nurture entrepreneurship.

2. Mode 3 knowledge production: based on a systemtheoretic perspective in which knowledge is molded, remixed, shared, and applied within a knowledgedriven society.

Assumption: quintuple helix ecosystems are knowledge production, distribution, and application systems in which knowledge is generated through the exchange of knowledge between actors in the ecosystem (Carayannis \& Campbell, 2012).

3. A system of subsystems: the quintuple helix ecosystem encompasses the different domains that resonate and collaborate to solve mutual challenges.

Assumption: each ecosystem actor provides unique resources to the ecosystem, but also mixes, translates, and processes resources from others. The quintuple helix model describes five societal subsystems (Carayannis et al., 2012): i) the educational system, which generates and disseminates new knowledge; ii) the economic system, which controls, possesses, and generates economic capital; iii) the political system, which has political and legal capital (e.g., laws, clearances, policy, public goods); iv) civil society, which has social capital, and is characterized by traditions, values, and behavioural patterns; and v) the natural environment, which has natural capital (e.g., natural resources, climate, air quality, geological stability).

4. Socio-ecological transition: the main contribution of the quintuple helix model is the integration of the natural environment, which is conceptualized as a contextualization of the four helices of the quadruple helix.

Assumption: if this context is taken into account, it is possible to achieve sustainable socio-ecological transition, creating synergies between economy, society, and democracy (Carayannis \& Campbell, 2011).

\section{Analysis}

\section{Quintuple helix innovation in a structured process}

An urban living lab follows a structured process in which a central problem, idea, concept, or prototype is at the heart of the collaboration. This innovation development process implements a combination of different methodologies (e.g., for Project A: interviews, focus groups, surveys, co-creation workshops, online crowdsourcing, and a field trial) to involve a wide variety of stakeholders (e.g., for Project A: different local government divisions, citizens, civil society organizations, large and small research organizations, and startups). As described earlier, this formal but flexible staged process was, in both cases, instigated by the eco-entrepreneurs, was financially supported by the Flemish government, and was managed by iMinds Living Labs, a semi-public living lab organization, embedded in an interdisciplinary and cross-university, technology-driven research centre. The formal living lab process structured the innovation development and governed stakeholder interaction, knowledge production, and knowledge transfer. For example, the process facilitated steering committees, safeguarded the overall planning and resources of the project, leveraged social capital within the different subsystems, provided coaching and implementation resources, and translated knowledge between ecosystem stakeholders. 


\section{Quintuple Helix Innovation: Urban Living Labs and Socio-Ecological Entrepreneurship}

Bastiaan Baccarne, Sara Logghe, Dimitri Schuurman, and Lieven De Marez

\section{Innovation diplomacy}

The formal commitments within both cases were limited to the eco-entrepreneurs and the semi-public living lab management organization. However, both cases also had semi-formal commitments from their respective local governments. Both projects were unable to convince other key actors in the ecosystem to become a formal partner of the project because these other actors were not willing to commit themselves to an uncertain and open project. However, once the project gained momentum and tangibility, collaborations were still possible on an ad hoc basis. Not only were key stakeholders eventually attracted to the ecosystem, but also several unexpected smaller institutions (i.e., research institutes, companies, and civic organizations), who were very willing to contribute and share their knowledge. The ad hoc, open-ended, and semi-formal design of these temporal collaboration networks served as an risk reducing characteristic and helped to overcome collaboration barriers. As such, the collaborative design of the urban living lab stakeholder ecosystem acted as a centripetal force within the urban environment, as acupuncture to congregate urban actors with similar goals. Although every collaborator had their own agenda (e.g., leveraging their own business, connecting with the local government, pushing local change), this did not interfere with the overall goals of the project.

Finally, when it came to the involvement of the local government, the process facilitated access and interaction with different governmental levels. The deployment of a temporal experimental window, which was considered "neutral" and "external" to existing organizations, enabled individuals to detach themselves from restraining organizational structures and collaborate in a more agile environment, and to stretch the boundaries of what is generally possible (e.g., temporarily sharing data sources, talking freely outside the governmental organization, providing favourable exceptions on the use of public space).

\section{Mode 3 knowledge production}

In the air quality domain (Project A), a lot of knowledge is generated in mode 1 . Traditionally, research institutes obtain grants to study atmospheric particulate matter (e.g., as PM2.5) or ozone concentrations. Most of these data remain hidden to the public. However, there are some initiatives that attempt to disseminate these data to civil society. Most of the time, these initiatives are built upon open data principles and are, for example, translated in dashboards showing air quality values. In theory, these initiatives distribute and apply mode 1 knowledge (potentially generating mode 2 knowledge).
However, this information cannot be interpreted by actors outside the knowledge domain (e.g., regular citizens). Even if the raw numbers are translated in visual information (e.g., public visualizations of the air quality have been created in the city of Project A), the academic complexity was not interpretable for citizens and citizens had no idea how to act upon this information.

Through an iterative, multi-method research approach, the (tacit) knowledge of all stakeholders could be captured, exchanged, (re)combined, mixed, and molded. By distributing and translating fundamental chunks of knowledge to actors outside the original knowledge domain, unexpected but valuable interpretations and interactions occurred. However, such "sparks" and often volatile knowledge must be adequately captured and managed to contribute to the project goal. For Project A, this process of knowledge capture resulted in the development a conceptual model for socio-ecological change, which served as the basis for design requirements and the development of the project prototypes. Project B, on the other hand, focused on understanding end-user needs and frustrations in relation to technological evolutions and other stakeholder needs and knowledge, mainly to set-up a field trial experiment that matched the usage context. These insights were necessary for both practical and substantial reasons in order to be able to test the electric-car sharing system.

\section{The ecosystem and circulation of knowledge}

In both cases, various exchanges between different knowledge domains took place. Some examples include knowledge transfers from the political system to the economic system (i.e., knowledge regarding policy, internal procedures, the value network, and business model opportunities) and from civil society to both the educational system (e.g., the interpretation of complex data by citizens and the relation to their everyday behaviour) and the economic system (i.e., regarding needs and adoption potential). Furthermore, for the local government, the urban living lab projects also bridged different divisions and individuals within the organization (e.g., different divisions were working on open data and air quality for some time, but it took the project to connect them and expose the overlap between their efforts). This bridging can be conceptualized as an intra-organizational centripetal force, which is the mobilizing effect of an urban living lab within an organization to connect like-minded individuals beyond organizational structures. As such, the projects facilitated horizontal and agile collaboration and knowledge exchange on an ad hoc basis, largely bypassing traditional structures and processes. 


\section{Quintuple Helix Innovation: Urban Living Labs and Socio-Ecological Entrepreneurship} Bastiaan Baccarne, Sara Logghe, Dimitri Schuurman, and Lieven De Marez

\section{Socio-ecological transition}

As for the "natural context", both projects aimed to interact with the socio-ecological environment through their environmental goals. Against this backdrop, it makes sense to conceptually model the innovation ecosystem using the quintuple helix model. Using this framework, it is clear that (urban) innovation is related to issues regarding the socio-ecological context in which we live and (co-)develop our common sociotechnological future. Neglecting this dimension is a failure to contextualize innovation development in a broader environment. Although this model fits with the theoretical understanding of urban living labs, they in turn offer an implementation approach for the quintuple helix model for innovation.

Concerning sustainability, both projects exposed the difficulty of designing viable business models in a "public" domain. Both civil society and the economic system consider it the duty of the political system to take responsibility. However, the political system is facing decreasing resources, which makes it hard to develop a sustainable business model. For Project B, this challenge resulted in the establishment of a cooperative organization with limited liability. Different actors who were previously involved in the urban living lab became members of this organization. As such, some of the social capital that was generated within the urban living lab was leveraged to help sustain the innovation.

Nevertheless, socio-ecological transition must also be considered in a broader sense. Through (series of) experiments, project-based quintuple helix innovation can foster long-term change on a more latent level, by inspiring and stimulating debate on contemporary urban challenges and solutions. Applied to the socio-ecological systems way of thinking, urban living labs contribute to the resistance of an urban socio-ecological system. More specifically, this goal is achieved through the facilitation of flexible and agile experimentation with possible solutions for issues related to "system stress" caused by urbanization itself, and by doing so, adding to a long-term and latent social transition that is closely interrelated with ecological concerns and associated knowledge.

\section{Conclusions and Discussion}

This article bridges the theoretical propositions of the quintuple helix model and the practice-based concept of urban living labs. More specifically, we discussed the concepts of innovation diplomacy, mode 3 knowledge production, the innovation ecosystem as a system of subsystems (related to the circulation of knowledge), and socio-ecological transition to analyze the urban living lab approach. Our findings largely support the theoretical assumptions of the quintuple helix model and elaborate on the urban living lab approach as a way to put this model into practice at the level of a single innovation development process. Urban living labs can be a way to work with ad hoc collectives, lowering the barriers for collaboration. The project-centric nature is a catalyst for knowledge exchange and collaborations within and outside the project and involved organizations.

A successful urban living lab can facilitate and balance top-down governance with bottom-up initiatives in the city. However, some challenges remain. Whereas experimental urban living lab activities activate and reinforce the quintuple helix ecosystem, it is still hard to harness the creation potential within the city in a sustainable way. Nevertheless, urban living labs facilitate urban transitions through an accumulation of experiments, which allow urban actors to experience change, leading to transitions in the long run. This logic suggests that urban living labs contribute to (long-term) sustainable socio-ecological transition, which is mainly facilitated by an interdisciplinary (and transdisciplinary) temporal experimental window that promotes collaborative learning and stakeholder engagement. However, although value is being created at the meso level (i.e., the project level), there is a need for a more formal value capture and retention processes at the macro level (i.e., the level of ecosystems and the overarching organization). In the urban context, it makes sense that local governments fulfil such a role. This is to some extent in line with the conceptualization of the government as a platform (O'Reilly, 2011).

The quintuple helix is a useful concept to understand and analyze how knowledge is created and exchanged in an urban environment, which can be studied as a collaborative innovation development ecosystem, while also taking the ecological context into account. Although such awareness is growing in most organizations, this dimension is not present in most distributed innovation theories and processes. An urban living lab thus can generate and evolve tacit and codified knowledge while focusing on the exchange of knowledge within a natural environment system. In this way, both the innovation outcomes and the urban socio-ecological transition can become more sustainable and recover ecological balance, thus ensuring the quality of life for future generations. 


\section{Quintuple Helix Innovation: Urban Living Labs and Socio-Ecological Entrepreneurship}

Bastiaan Baccarne, Sara Logghe, Dimitri Schuurman, and Lieven De Marez

\section{About the Authors}

Bastiaan Baccarne is a Research and Teaching Assistant at iMinds-MICT, a research group within the communications department of Ghent University, where he works on the topic of user-centric innovation development in the context of (new) media and ICT. Bastiaan is also a PhD student working on citizen empowerment through the co-development of socio-technical innovations in an urban environment. Being part of iMinds Living Labs, Bastiaan works as a user researcher for several SME and startup projects, with an overall academic focus on the possibilities and limitations of user-centric innovation development ecosystems.

Sara Logghe obtained a master's degree in both History and Communication Sciences with specialization in New Media and Society at Ghent University. Her second master's thesis was Cultural Communication on the Internet: A Study on the Potential of Social Media for Cultural Institutions. A three-month internship at iMinds Living Labs encouraged her interest in research on living labs, and in May 2013, Sara joint iMinds-MICT as a Junior Researcher. Working on cultural projects within living lab research, Sara developed a specific interest in the changing library scene.

Dimitri Schuurman holds a PhD (2015) and Master's in Communication Sciences (2003) from Ghent University in Belgium. He joined the research group iMinds - MICT - Ghent University in 2005 and started working at iMinds Living Labs in 2009. Together with his iMinds colleagues, Dimitri developed a specific living lab offering targeted at startups and SMEs, in which he has managed over 50 innovation projects. As a senior researcher, Dimitri is currently responsible for the methodology and academic valorization of living lab projects. He also coordinates a dynamic team of living lab researchers from iMinds - MICT - Ghent University. His main interests and research topics are situated in the domains of open innovation, user innovation, and innovation management. In early 2015, he finished his PhD entitled Bridging the Gap between Open and User Innovation? Exploring the Value of Living Labs as a Means to Structure User Contribution and Manage Distributed Innovation.
Lieven De Marez is Research Director of the iMinds Media \& ICT (MICT) research group and teaches on the topics of innovation research, media, market and ICT, and new communication technologies in the Department of Communication Sciences at Ghent University in Belgium. MICT is one of 16 research groups within iMinds, and Lieven is also part of the management team of iMinds Living Labs' facilitating infrastructure for living lab research.

\section{References}

Atkinson, R. 1998. Technological Change and Cities. Cityscape, 3(3): 129-170.

http://www.jstor.org/stable/20868462

Baccarne, B., Mechant, P., Schuurman, D., Colpaert, P., \& De Marez, L. 2014. Urban Socio-Technical Innovations With and By Citizens. Interdisciplinary Studies Journal, 3(4): 143-156.

Berkes, F., Colding, J., \& Folke, C. (Eds.). 2002. Navigating Social-Ecological Systems. Cambridge: Cambridge University Press.

http://dx.doi.org/10.1017/cbo9780511541957

Berkes, F., Folke, C., \& Colding, J. (Eds.). 2000. Linking Social and Ecological Systems: Management Practices and Social Mechanisms for Building Resilience. Cambridge: Cambridge University Press.

Bocquier, P. 2005. World Urbanization Prospects. Demographic Research, 12: 197-236.

http://dx.doi.org/10.4054/demres.2005.12.9

Bogers, M., \& West, J. 2012. Managing Distributed Innovation: Strategic Utilization of Open and User Innovation. Creativity and Innovation Management, 21(1): 61-75.

http://dx.doi.org/10.1111/j.1467-8691.2011.00622.x

Buscher, V., Tomordy, M., Ashley, G., \& Tabet, M. 2010. Smart Cities: Transforming the 21st Century City Via the Creative Use of Technology. London: Arup IT \& Communication Systems.

Carayannis, E. G., Barth, T. D., \& Campbell, D. F. 2012. The Quintuple Helix Innovation Model: Global Warming as a Challenge and Driver for Innovation. Journal of Innovation and Entrepreneurship, 1(2): 2.

http://dx.doi.org/10.1186/2192-5372-1-2

Carayannis, E. G., \& Campbell, D. F. 2009. Mode 3 and Quadruple Helix: Toward a 21st Century Fractal Innovation Ecosystem. International Journal of Technology Management, 46(3): 201-234. http://dx.doi.org/10.1504/ijtm.2009.023374

Carayannis, E. G., \& Campbell, D. F. 2010. Triple Helix, Quadruple Helix and Quintuple Helix and How Do Knowledge, Innovation and the Environment Relate To Each Other? A Proposed Framework for a Trans-disciplinary Analysis of Sustainable Development and Social Ecology. International Journal of Social Ecology and Sustainable Development, 1(1): 41-69.

http://dx.doi.org/10.4018/jsesd.2010010105 


\section{Quintuple Helix Innovation: Urban Living Labs and Socio-Ecological Entrepreneurship}

\section{Bastiaan Baccarne, Sara Logghe, Dimitri Schuurman, and Lieven De Marez}

Carayannis, E. G., \& Campbell, D. F. J. 2011. Open Innovation Diplomacy and a 21st Century Fractal Research, Education and Innovation (FREIE) Ecosystem: Building on the Quadruple and Quintuple Helix Innovation Concepts and the "Mode 3" Knowledge Production System. Journal of the Knowledge Economy, 2(3): 327-372. http://dx.doi.org/10.1007/s13132-011-0058-3

Carayannis, E. G., \& Campbell, D. F. J. 2012. Mode 3 Knowledge Production in Quadruple Helix Innovation Systems. New York, NY: Springer New York.

http://dx.doi.org/10.1007/978-1-4614-2062-0

Chesbrough, H. W. 2003. Open Innovation: The New Imperative for Creating and Profiting from Technology. Boston: Harvard Business School Press.

De Moor, K., Berte, K., De Marez, L., Joseph, W., Deryckere, T., \& Martens, L. 2010. User-Driven Innovation? Challenges of User Involvement in Future Technology Analysis. Science and Public Policy, 37(1): 51-61.

http://dx.doi.org/10.3152/030234210x484775

Eisenhardt, K. 1989. Building Theories from Case Study Research. Academy of Management Review, 14(4): 532-550. http://dx.doi.org/10.2307/258557

Eriksson, M., Niitamo, V., Kulkki, S., \& Hribernik, K. 2006. Living Labs as a Multi-Contextual $R \& D$ Methodology. 12th International Conference on Concurrent Enterprising: Innovative Products and Services through Collaborative Networks, ICE 2006. Milan, Italy.

Etzkowitz, H., \& Leydesdorff, L. 1995. The Triple Helix: University-Industry-Government Relations: A Laboratory for Knowledge-Based Economic Development. EASST Review, 14(1): $14-19$.

Etzkowitz, H., \& Leydesdorff, L. 2000. The Dynamics of Innovation: From National Systems and "Mode 2" to a Triple Helix of University-Industry-Government Relations. Research Policy, 29(2): 109-123.

http://dx.doi.org/10.1016/s0048-7333(99)00055-4

Feurstein, K., Hesmer, A., Hribernik, K., Thoben, T., \& Schumacher, J. 2008. Living Labs: A New Development Strategy. In J. Schumacher \& V. P. Niitamo (Eds.), European Living Labs - A New Approach for Human Centric Regional Innovation. Berlin, Germany: Wissenschaftlicher.

Følstad, A. 2008. Living Labs for Innovation and Development of Communication Technology: A Literature Review. The Electronic Journal for Virtual Organisations and Networks, 10: 99-131.

Foth, M. 2009. Handbook of Research on Urban Informatics: The Practice and Promise of the Real-Time City. Hershey, PA: IGI Global. http://dx.doi.org/10.4018/978-1-60566-152-0

Franz, Y. 2014. Chances and Challenges for Social Urban Living Labs in Urban Research. ENoLL OpenLivingLab Days 2014 Conference Proceedings: 105-114. Amsterdam, Netherlands.

Frissen, V., \& Lieshout, M. 2004. To User-Centred Innovation Processes: The Role of Living Labs. Delft, TNO-ICT.

Gibbons, M., Limoges, C., Nowotny, H., Schwartzman, S., Scott, P., \& Trow, M. 1994. The New Production of Knowledge: The Dynamics of Science and Research in Contemporary Societies. London: Sage. http://dx.doi.org/10.4135/9781446221853
Godin, B., \& Gingras, Y. 2000. The Place of Universities in the System of Knowledge Production. Research Policy, 29(2): 273-278. http://dx.doi.org/10.1016/s0048-7333(99)00065-7

Juujärvi, S., \& Pesso, K. 2013. Actor Roles in an Urban Living Lab: What Can We Learn from Suurpelto, Finland? Technology Innovation Management Review, 11(3): 22-27. http://timreview.ca/article/742

Kviselius, N., Ozan, H., Edenius, M., \& Andersson, P. 2008. The Evolution of Living Labs-Propositions for Improved Design and Further Research. 5th International Conference on Innovation and Management (ICIM 2008): 842-856. Maastricht, The Netherlands.

Machlis, G., Force, J., \& Burch, W. J. 1997. The Human Ecosystem Part I: The Human Ecosystem as an Organizing Concept in Ecosystem Management. Society \& Natural Resources, 10(4): 347-367. http://dx.doi.org/10.1080/08941929709381034

Niitamo, V., \& Kulkki, S. 2006. State-of-the-Art and Good Practice in the Field of Living Labs. Proceedings of the 12th International Conference on Concurrent Enterprising: Innovative Products and Services through Collaborative Networks: 349-357. Milan, Italy.

Nowotny, H., Scott, P., \& Gibbons, M. 2003. Introduction: "Mode 2" Revisited: The New Production of Knowledge. Minerva, 41(3): 179-194.

O'Flynn, J. 2007. From New Public Management to Public Value: Paradigmatic Change and Managerial Implications. Australian Journal of Public Administration, 66(3): 353-366. http://dx.doi.org/10.1111/j.1467-8500.2007.00545.x

O'Reilly, T. 2011. Government as a Platform. Innovations: Technology, Governance, Globalization, 6(1): 13-40.

http://dx.doi.org/10.1162/INOV_a_00056

Paskaleva, K. 2011. The Smart City: A Nexus for Open Innovation? Intelligent Buildings International, 3(3): 153-171. http://dx.doi.org/10.1080/17508975.2011.586672

Pierson, J., \& Lievens, B. 2005. Configuring Living Labs for a "Thick" Understanding of Innovation. Ethnographic Praxis in Industry Conference Proceedings, (1): 114-127. http://dx.doi.org/10.1111/j.1559-8918.2005.tb00012.x

Reason, P., \& Bradbury, H. 2001. Handbook of Action Research: Participative Inquiry and Practice. London: Sage Publications.

Rits, O., Schuurman, D., \& Ballon, P. 2015. Exploring the Benefits of Combining Business Modelling with Living Labs. The XXVI ISPIM Conference - Shaping the Frontiers of Innovation Management, Budapest, Hungary on 14-17 June 2015, (June).

Schaffers, H., \& Budweg, S. 2009. A Living Lab Approach for Enhancing Collaboration in Professional Communities. Proceedings of the International Conference on Concurrent Enterprising. Leiden, The Netherlands.

Schumacher, J., \& Niitamo, V. P. (Eds.). 2008. European Living Labs: A New Approach for Human Centric Regional Innovation. Berlin, Germany: Fachhochschule Verlag Berlin.

Schuurman, D. 2015. Bridging the Gap between Open and User Innovation? Exploring the Value of Living Labs as a Means to Structure User Contribution and Manage Distributed Innovation. Doctoral dissertation, Ghent University, Belgium. 


\section{Quintuple Helix Innovation: Urban Living Labs and Socio-Ecological Entrepreneurship Bastiaan Baccarne, Sara Logghe, Dimitri Schuurman, and Lieven De Marez}

Schuurman, D., Baccarne, B., Kawsar, F., Seys, C., Veeckman, C., et al. 2013. Living Labs as Quasi-experiments: Results from the Flemish LeYLab. XXIV ISPIM Conference - Innovating in Global Markets: Challenges for Sustainable Growth, (June). Helsinki, Finland.

Schuurman, D., Lievens, B., De Marez, L., \& Ballon, P. 2012. Towards Optimal User Involvement in Innovation Processes: A PanelCentered Living Lab-approach. Proceedings of PICMET'12, 2046-2054.

Ståhlbröst, A. 2008. Forming Future IT - The Living Lab Way of User Involvement. Doctoral dissertation, Luleå University of Technology, Sweden.

Ståhlbröst, A., \& Holst, M. 2012. The Living Lab Methodology Handbook. Luleå, Sweden: Luleå University of Technology and Centre for Distance-Spanning Technology (CDT).
Viitanen, J., \& Kingston, R. 2014. Smart Cities and Green Growth: Outsourcing Democratic and Environmental Resilience to the Global Technology Sector. Environment and Planning A, 46(4): 803-819.

http://dx.doi.org/10.1068/a46242

Yin, R. 1984. Case Study Research. Beverly Hills, CA: Sage Publications.

Young, O. R., Berkhout, F., Gallopin, G. C., Janssen, M. A., Ostrom, E., \& van der Leeuw, S. 2006. The Globalization of Socio-Ecological Systems: An Agenda for Scientific Research. Global Environmental Change, 16(3): 304-316.

http://doi.org/10.1016/j.gloenvcha.2006.03.004

Citation: Baccarne, B., Logghe, S., Schuurman, D., \& De Marez, L. 2016. Governing Quintuple Helix Innovation: Urban Living Labs and Socio-

Ecological Entrepreneurship. Technology Innovation Management Review, 6(3): 22-30. http://timreview.ca/article/972

Keywords: distributed innovation, quintuple helix innovation, social ecology, socio-ecological entrepreneurship, urban living labs 